Enquist et al. reply - Energy equivalence, as originally defined ${ }^{1}$, was an empirical relationship observed in animals: species differing in body mass, $M$, by many orders of magnitude tend to have almost equal rates of energy use per unit area by the population, because of an inverse allometric scaling relationship between energy use by the individual, or its metabolic rate, $B$, and the maximal population density, $N_{\max }$. Because $B \propto M^{3 / 4}$ and $N_{\max } \propto M^{-3 / 4}$, energy use is proportional to $B N_{\max } \propto M^{3 / 4} M^{-3 / 4} \propto M^{0}$.

We have shown that this also holds for plants ${ }^{2}$, namely that the allometric scaling of both $B$ and $N_{\max }$ appear to be the same as in animals. Further, we showed that the scaling of population density, and the resulting energy equivalence, can be explained by a simple model that assumes that plants grow until the allometric rates of resource use by the population equals the rate of resource supply.

In previous work, this was far from clear. The traditional explanation of the thinning law was not based on rates of individual resource use, but was thought to result from the geometric packing of canopies ${ }^{3}$ so that $N \propto M^{-2 / 3}$, or to be due to biomechanical constraints and the accumulation of nonliving material ${ }^{4}$ so that $N \propto M^{-3 / 4}$. None of these studies, including that of Dewar ${ }^{5}$, has predicted the scaling of individual resource use. We not only make this explicit prediction, but also derive it from a model of resource distribution in plants with fractallike branching structures ${ }^{6}$.

Dewar implies that energy equivalence reflects the fact that essentially all of the light is intercepted by closed canopies, and that growth rates of plants per unit of radiation are invariant. We agree, and in fact this is a special case of our general argument. Furthermore, we now have a detailed quantitative whole-plant model of resource distribution from which the general derivation of energy equivalence follows ${ }^{7}$. This model assumes that the size and photosynthetic rate of leaves are independent of plant mass. It predicts the number of leaves to be proportional to $B$, which is proportional to $M^{3 / 4}$. This is exactly the condition needed to give the density-mass relationship and therefore energy equivalence. But our model is much more general because it also applies to populations in which canopies are not closed and where water or nutrients, as well as light (as claimed by Dewar), are the critical limiting resources.

Dewar correctly observes that there may be a slight decrease in production or growth following canopy closure during secondary succession. But this is a point of detail. The hundred-fold variation in resource use, including any possible decline in production associated with age, is very small compared with the trillion-fold variation in vascular plant size. We emphasized that ecosystems such as adjacent grasslands and forests, which have similar rates of resource supply but are dominated by plants differing by many orders of magnitude in mass, typically have similar rates of primary production. This does not seem to have been appreciated, despite work on relationships between population density and plant size and between individual plant performance and ecosystem productivity.

We agree with Magnani that transpiration and plant metabolism are influenced by local environmental conditions, especially when comparisons are made between individuals of relatively similar size $e^{8,9}$. This accounts, for example, for the nearly two orders of magnitude variation in productivity of ecosystems dominated by similarly sized plants (our Fig. 4 in ref. 2); a good example would be to compare Arctic tundra with tropical grassland. Organism transpiration and metabolism, however, are even more strongly influenced by plant size (our Fig. 1). Thus, rates of xylem flux vary by only about two orders of magnitude as plant mass varies by 12 orders of magnitude from the smallest herbs and seedlings to the largest trees.

The rates of evaporation for ecosystems (our Fig. 4) are near-maximal short-term rates measured for individuals of known size of different plant species under nearoptimal conditions. A few of these values are indeed higher than rates reported for ecosystems averaged over longer periods of months to years. Given this caveat, it is impressive that our estimates obtained by scaling up from individual plants (max, $82.41 \mathrm{~m}^{-2}$ per day; $\min , 1.01 \mathrm{~m}^{-2}$ per day; mean, $16.31 \mathrm{~m}^{-2}$ per day, s.d. 16.44) are within an order of magnitude of the maximum reported values. Most values fall within the range obtained using different sampling techniques, including remote sensing, for estimating the productivity of entire ecosystems ${ }^{10}$.

We therefore disagree with Magnani's objection to our extrapolation of the consequences of allometric scaling at the level of individual plants to processes that operate at the level of populations and ecosystems ${ }^{11}$. Allometric relationships are not useful for understanding small differences in performance among similarly sized plants, such as forest trees following canopy closure. Allometry is invaluable, however, for understanding the pervasive effects of plant size on such diverse phenomena as the structure of single- and mixed-species stands, or on the productivity of ecosystems dominated by plants of contrasting size, such as adjacent agricultural fields, grasslands and forests. Understanding quarterpower allometric scaling relations at different levels of biological organization (in both plants and animals) will contribute to a common explanation of how body size influences the acquisition and allocation of resources and thereby affects the abundance, distribution and diversity of sizes.

Brian J. Enquist ${ }^{\star}$, James H. Brown*, Geoffrey B. West $\dagger$

The Santa Fe Institute, 1399 Hyde Park Road,

Santa Fe, New Mexico 87501, USA

* Department of Biology, University of New Mexico, Albuquerque, New Mexico 87131, USA

$\dagger$ Theoretical Division, T-8, MS B285,

Los Alamos National Laboratory,

Los Alamos, New Mexico 87545, USA

1. Damuth, J. Nature 290, 699-700 (1981).

2. Enquist, B. J., Brown, J. H. \& West, G. B. Nature 395, 163-165 (1998).

3. Yoda, K., Kira, T., Ogawa, H. \& Hozumi, K. J. Biol. Osaka City Univ. 14, 107-129 (1963)

4. Franco, M. \& Kelly, C. K. Proc. Natl Acad. Sci. USA 95, 7830-7835 (1998)

5. Dewar, R. C. Ann. Bot. 71, 147-159 (1993).

6. West, G. B., Brown, J. H. \& Enquist, B. J. Science 276, 122-126 (1997).

7. Enquist, B. J., West, G. B. \& Brown, J. H. in Scaling in Biology (eds Brown, J. H. \& West, G. B.) (Oxford Univ. Press, in the press).

8. Kozlowski, T. T. \& Pallardy, S. G. Physiology of Woody Plants (Academic, New York, 1997).

9. Lambers, H., Chapin, F. S. I. \& Pons, T. L. Plant Physiological Ecology (Springer, New York, 1998).

10. Schulze, E. D., Kelliher, F. M., Korner, C., Lloyd, J. \& Leuning, R. Annu. Rev. Ecol. Syst. 25, 629-660 (1994).

11. Ehleringer, J. R. \& Field, C. B. Scaling Physiological Processes: Leaf to Globe (Academic, New York, 1993).

\section{Biostratigraphy of new pterosaurs from China}

Pterosaurs are represented in China by five genera and some isolated bones ranging in age from the Middle Jurassic to the Late Cretaceous period ${ }^{1,2}$. Four of these genera belong to the derived monophyletic subgroup Pterodactyloidea; only the Middle Jurassic Angustinaripterus from Dashanpu, Sichuan, is a non-pterodactyloid (traditionally 'rhamphorhynchoids', a paraphyletic taxon). Two further pterosaurs ${ }^{1,2}$ (Fig. 1) from the Chaomidianzi Formation of the Beipiao area, western Liaoning Province, occur in the Liaoning beds, several metres higher than the compsognathid coelurosaur Sinosauropteryx and the basal bird Confuciusornis. Our analysis of these two fossils and other components of the fauna suggest a Late Jurassic biostratigraphic age for the Liaoning beds, which are important in the study of avian origins.

One new pterosaur, Dendrorhynchus curvidentatus $^{1}$, is morphometrically most similar to the Late Jurassic (Tithonian) Solnhofen form Rhamphorhynchus but does not fit within that taxon. Principal components analysis (by K. I. Warheit and K. P.) (Fig. 2) of the long bones of various pterosaurs indicates that Dendrorhynchus clusters most closely with Rhamphorhynchus and has no obvious unique features, but its proportions differ from those 


\section{scientific correspondence}
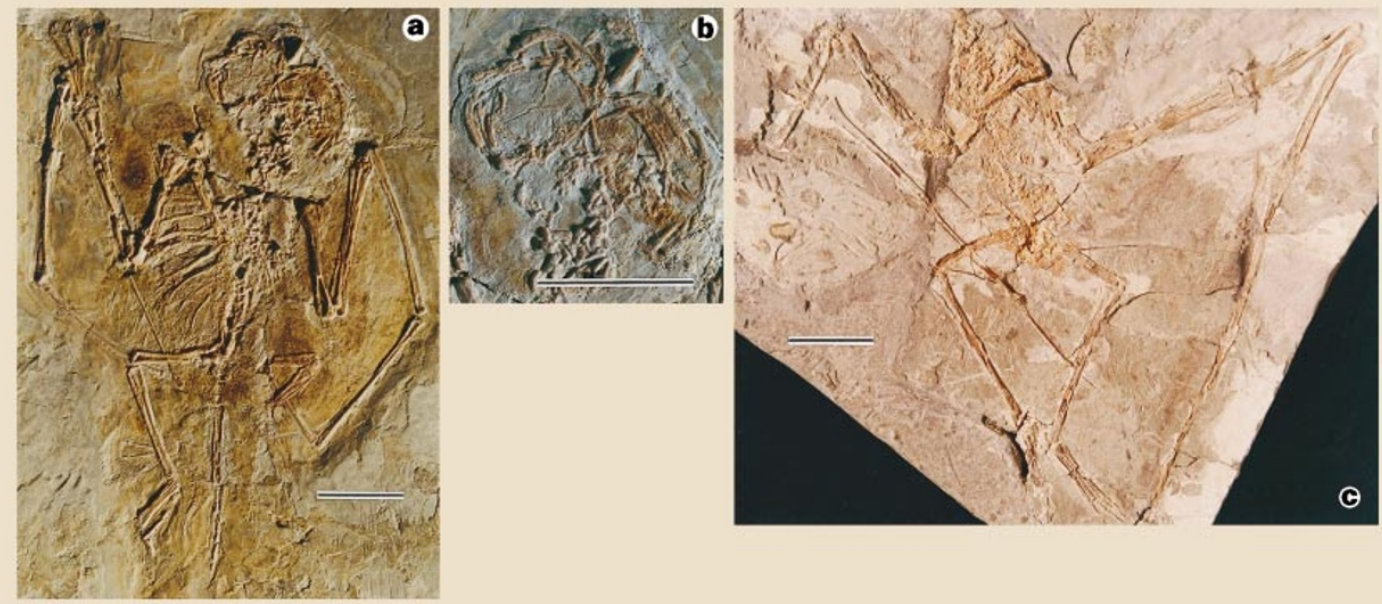

Figure 1 The new Liaoning pterosaurs. a, Dendrorhynchoides ("Dendrorhynchus") curvidentatus n. g. (Ji \& ji, 1998) (holotype, National Geological Museum of China GMV2128). Scale bar, $20 \mathrm{~mm}$. b, Detail of $D$. curvidentatus skull. Scale bar, $20 \mathrm{~mm}$. c Pterodactylus ("Eosipterus") yangi Ji \& Ji, 1997 (holotype, GMV2117). Scale bar, $50 \mathrm{~mm}$.

of the ontogenetic trajectories of Rhamphorhynchus. Instead, like Scaphognathus, it is distinct at the generic level. The generic name Dendrorhynchus is preoccupied by a nemertine ${ }^{3}$, so we propose replacing it with the name Dendrorhynchoides.

The second new fossil, Eosipterus yangi ${ }^{2}$ (Fig. 1c), is a large pterodactylid with a wingspan of about 1.25 metres. The incomplete fusion of the carpals and tarsals indicates that this specimen, although large for a pterodactylid, was not fully adult. A plot of the second and third principal components (the first was size) of the preserved long bones of Eosipterus (Fig. 2) groups Eosipterus with the Late Jurassic Solnhofen pterodactylids Pterodactylus kochi, $P$. antiquus and Germanodactylus, which have been viewed as part of a single ontogenetic series $^{4}$ of $P$. antiquus, with which Eosipterus may be synonymous.

The age of the Liaoning beds has been argued to be Late Jurassic or Early Cretaceous, and radiometric dates give conflicting results ${ }^{5}$. The biostratigraphy of the fauna through the entire section of the Yixian and Chaomidianzi formations is ambiguous. At Sihetun (in the Beipiao area), fish, frogs, turtles, lizards and mammals have been found, as well as theropod and sauropod (saurischian) and psittacosaurid (ornithischian) dinosaurs ${ }^{6,7}$. Among the theropods, Sinosauropteryx, Protarchaeopteryx, Caudipteryx and Confuciusornis ${ }^{8-10}$ are of primary importance to studies of the origins of birds and avian features.

When exact faunal equivalents are not available, next-of-kin taxa can provide at least minimal divergence times. Psittacosaurid dinosaurs have so far been known only from the Early Cretaceous ${ }^{7}$, but the separation of these marginocephalians from other ornithischian dinosaurs was no later than Early Jurassic, perhaps much earlier ${ }^{11}$. Sinosauropteryx is the most closely related of the Liaoning coelurosaurs to the Late Jurassic basal coelurosaur Compsognathus from the Solnhofen limestones of Germany ${ }^{8}$. Protarchaeoptery $x^{3}$ is a basal maniraptoran, as are avians such as the Solnhofen form

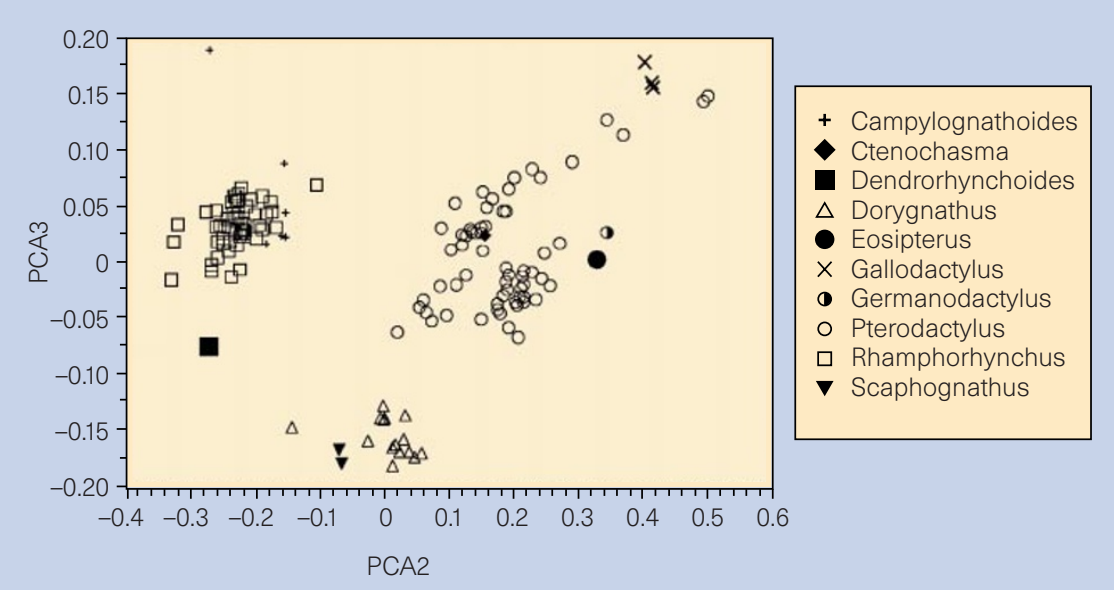

Figure 2 Principal components analysis (PCA). PCA plot of second and third major axes, comparing radius, wing metacarpal, first two wing phalanges, and tibia in Campylognathoides, Ctenochasma, Dendrorhynchoides', Dorygnathus, "Eosipterus", Gallodactylus, Germanodactylus, Pterodactylus, Rhamphorhynchus and Scaphognathus. Dendrorhynchoides differs significantly from Rhamphorhynchus along the third major axis; "Eosipterus" falls within the cluster of points of the congenerics Pterodactylus, Germanodactylus and Ctenochasma ${ }^{4}$ for pairwise comparisons of PCAs $1-3$, and so is probably a large specimen of Pterodactylus (including Germanodactylus).
Archaeopteryx, and the Liaoning form Caudipteryx has been linked basally to these $\operatorname{taxa}^{3}$. Confuciusornis is the next most basal bird known after Archaeopteryx. The coelurosaurian lineages therefore provide a biostratigraphic signal of sister-taxa rooted in the Late Jurassic. None of these specific genera is known from the Early Cretaceous, although related lineages persisted.

The two new Liaoning pterosaurs provide a similar signal by clustering with Late Jurassic relatives. Pterodactyloids are known from both the Late Jurassic and the Cretaceous, but non-pterodactyloid pterosaurs are not reliably known from any Cretaceous deposits ${ }^{12}$. The Jurassic-Cretaceous transition among pterosaurs may therefore be sharper than in some other tetrapod faunal components, and the available data from coelurosaurs and particularly pterosaurs suggest a Late Jurassic age for the beds in which they are found. In contrast, the earliest Cretaceous faunas, such as that of the Wealden, bear little resemblance to the Liaoning and Solnhofen faunas ${ }^{13}$. But the most basal Cretaceous faunas must be better known before any biostratigraphic hypothesis can be considered iron-clad.

\section{S.-A. Ji, Q. Ji, K. Padian*}

National Geological Museum of China,

Xisi, Beijing 100034, China

${ }^{*}$ Department of Integrative Biology and Museum of Paleontology, University of California, Berkeley, California 94720-3140, USA

e-mail:kpadian@socrates.berkeley.edu

1. Ji, S.-A. \& Ji, Q. Jiangsu Geol. 22, 199-206 (1998).

2. Ji, S.-A. \& Ji, Q. Acta Geol. Sin. 71, 115-121 (1997).

3. Yin, Z. \& Zeng, F. Oceanol. Limnol. Sin. 16, 323-335 (1995).

4. Bennett, S. C. J. Vert. Paleontol. 16, 432-444 (1996).

5. Ji, Q. et al. Prof. Pap. Stratigr. Paleontol. (in the press)

6. Wang, X.-L. et al. Vert. PalAsiat. 36, 81-101 (1998).

7. Xu, X. \& Wang, Y. Vert. PalAsiat. 36, 147-158 (1998).

8. Chen, P.-J., Dong, Z.-M. \& Zhen, S.-N. Nature 391, 147-152 (1998)

9. Ji, Q., Currie, P. J., Norell, M. A. \& Ji, S.-A. Nature 393, 753-761 (1998).

10. Hou, L.-H., Martin, L. D., Zhou, Z.-H. \& Feduccia, A. Science 274, 1164-1167 (1996).

11. Padian, K. in Encyclopedia of Dinosaurs (eds Currie, P. J. \& Padian, K.) 549 (Academic, San Diego, 1997)

12. Padian, K. Modern Geol. 23, 57-68 (1998)

13. Norman, D. B. in Encyclopedia of Dinosaurs (eds Currie, P. J. \& Padian, K.) 783-785 (Academic, San Diego, 1997). 